\title{
Settlement during an earthquake in the un saturated crest of embankment on soft soil
}

\author{
B.Gordan, A.B.Adnan \\ 1. Faculty of civil Engineering, Universiti Teknologi Malaysia 81310 Skudai, Johor, Malaysia \\ 2. Head of Earthquake Department Universiti Teknologi Malaysia81310Skudai,Johor, Malaysia
}

\begin{abstract}
Due to evaluate of damages like to cracks in the embankment during an earthquake so cased to piping or overtopping and failure are main purpose. Review study indicated that the maximum displacement during dynamic loading is led to the crest and interaction between embankment with foundation or water was cased. Numerical analysis to investigate of relationship between material properties of the crest with unsaturated condition in short height embankment on the soft soil is performed. Analyses of models with plane strain were concerned by the finite-element method with ANSYS13 software so earthquake record as NAGAN with 5.02 second and peak ground acceleration equal to PGA=0.65g is used. Analysis of results in the main points indicated that to control dynamic settlement with minimum value of displacement in the vertical and horizontal axis and maximum shear stress in the foundation must follow from $\delta$ Ratio. This ratio was conducted to modulus elasticity between an unsaturated crest of embankment and soft soil in the foundation and this value between 0.13to0.20 Was defined and the best suggest of the ratio was $\delta=0.16$ to satisfy all the conditions. In addition, Numerical analysis had good agreements with literature review. Search more to evaluate the best value of this ratio for height embankment is a suggestion for future.
\end{abstract}

KEYWORDS: dynamic settlement, material properties, embankment, $\delta$ ratio, ANSYS softwar

\section{INTRODUCTION}

Due to behavior of embankment during dynamic loading so settlement control is required because, there are some damages like to cracks that cased to piping or overtopping and failure. Literature review indicated that since the beginning of 1920s and up to 1960s 'Pseudo-static method' of analysis was well-known. However, this method was very simple, and it not takes into account the nature of the slope-forming material or the foundation material. In the year 1965, based on deformation characteristics, NEWMARK [1] proposed 'Sliding block method'. Among other methods, 'Shear beam model' analysis was quite popular. This method was presented by MONONOBE [2]. GAZETAS [3] proposed an improved 'Inhomogeneous shear beam model' which can take care of the fact that the shear modulus in earth or rock-fill dams is not constant but increases with $2 / 3$ power of depth from the crest. CLOUGH and CHOPRA [4] performed the finite-element method for two-dimensional plane-strain analysis to estimate of the dynamic response of an embankment assuming that it consists of linearly elastic, homogeneous, isotropic materials. Later, several other researchers developed the finite-element and finite-difference method for non-linear, inelastic, non homogeneous, anisotropic behavior of materials under seismic loads. ZEGHAL and ABDEL-GHAFFAR [5] proposed a local-global finite element method of analysis for determination of the non-linear seismic behavior of earth dams. Ming and Li [6] conducted a fully coupled finite-element analysis of failure of Lower San Fernando dam and tested the possible reason of the dam failure. Quick development of computer programs had a useful data of earthquake engineering research. For instance, several computer programs like [7-11] were used widely for the intensive seismic analysis of embankment. Namdar et al[12] investigated seismic evaluation of embankment shaking table test and finite-element method so represented that there are good agreements between results of finite-element and experimental physical modeling. L. Wang et al[13] had been evaluated centrifuge model tests of Geotextile-reinforced soil embankments and introduced behavior of embankment during an earthquake. ZHU et al [14] and Brinkgreve et al[15] have evaluated a two-dimensional seismic stability for a levee embankment using finite element based program PLAXIS. Literature review indicated that the maximum displacement during dynamic loading is conducted to the crest and interaction between a dam, and foundation is cased to it. This paper considered effect of material properties in the unsaturated part of embankment on dynamic settlement at the end of construction and supplying water to control dynamic settlement during the earthquake with PGA=0.65g. 


\section{MODELING PROCESS}

Processes of models step by step with eight sub step for numerical dynamic analysis were considered.

2-1 Introduce Software

Ansys's software is comprehensive by finite-element method and has 100000 coadline. Even so, it is conducted to Computer Aided Engineering (CAE) and very strong to be connected with another software. Moreover, it is universal and popular in most of the finite-element software.

2-2 Elements

In this study, solid42 element for material of structures (embankment and foundation) and fluid79 element for water behind of the earth dam to model with plane strain 2D method according to recommended by ANSYS help menu were used.

2-3 Boundary conditions

To evaluate of dynamic analysis in models, Nagan earthquake is used with acceleration-time, and it was converted to displacement-time by SISMOSOFT3 software.After that, total displacement of the horizontal axis shown 0.43 meter in the end of dynamic load. Most of the famous records in the literature had a half value of the horizontal PGA for vertical axis. Therefore, value of the vertical displacement total equal to 0.2 meter is performed. In addition, vertical displacement in the horizontal boundary (bedrock) was zero and input data of NAGAN record is used for horizontal displacement of boundary. In add, both lines of vertical's boundary had a vertical total displacement equal to 0.2 meter and 0.01 meter for horizontal displacement so that it was led to transient property in the model to equilibrium elasticity conditions of waves.

2-4 Parametr of models

Table1 presented the parametric dimensional model for all the embankment models with different material properties in the saturate body.

Table1: A dimension of models.

$\mathrm{H}=30 \mathrm{~m} \quad \mathrm{~L}=108.92 \mathrm{~m} \quad \mathrm{~N}=36.37 \mathrm{~m} \quad H_{W}=21.00 \mathrm{~m} \quad \mathrm{~F}=9.00 \mathrm{~m} \quad \mathrm{Y}=15.00 \mathrm{~m} \quad \mathrm{~S}=5.00 \mathrm{~m}$

Parametric dimensional of models illustrated in Figure1 and earthquake is performed in the base of model and material properties like to Zones ( A, B, C, D and E) explained in Table2.

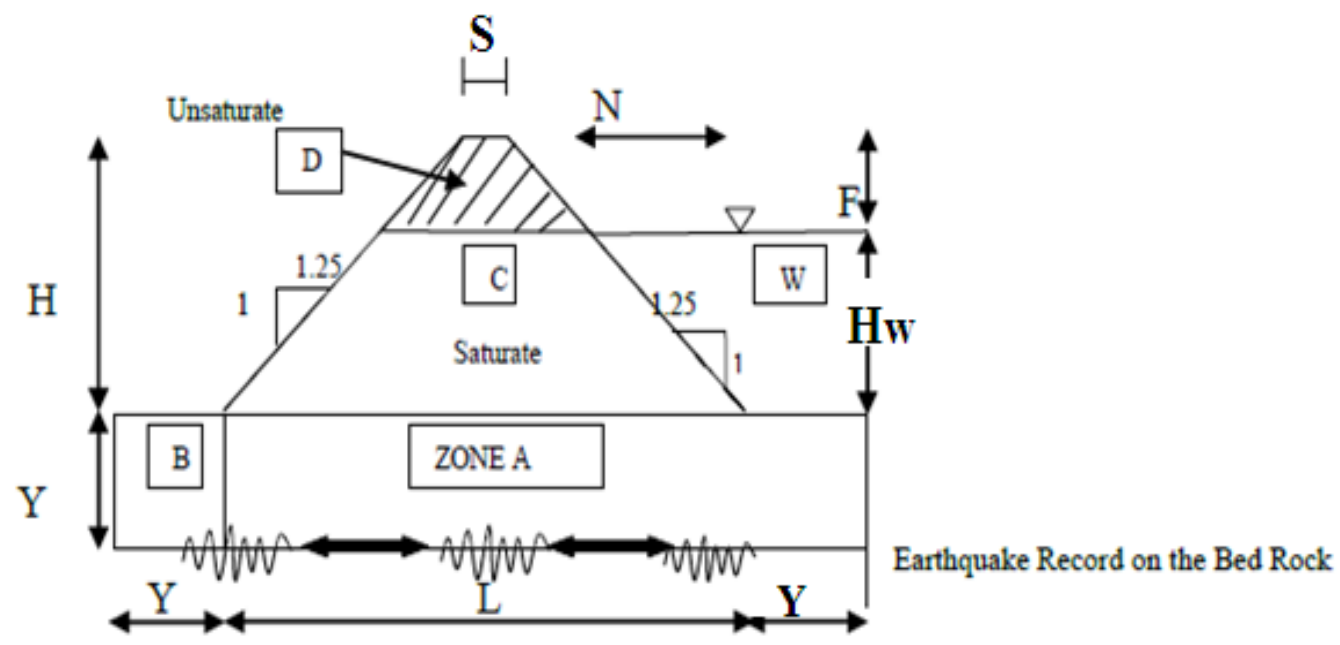

Fig. 1: A dimension of model according to Table 1for plan strain (2D) analaysis.

\section{2-5 Material Properties}

In this part introduced three section properties for water, foundation and embankment. Body of the structure was clay with isotropic property so material of foundation soft soil saturated (lose sand) was used. In addition, ANSYS LIQUID suggested that incompressible water according to Table2. Moreover, Table2 introduced material property in each zone of model and behavior of solid material was according to hardening isotropic bilinear so the friction coefficient was led to contact model for effect of interaction. It noted that models 1-3 were performed with (A, B, C, E and D1), (A, B, C, E and D2) and (A, B, C, E and D3) respectively. In add, to choose of value for soil properties is referenced by [17]. 


\begin{tabular}{|c|c|c|c|c|c|c|}
\hline Zone & $\begin{array}{l}\text { Relative } \\
\text { Density } \\
\left(\mathrm{Kg} / \mathrm{m}^{3}\right)\end{array}$ & $\begin{array}{l}\text { Elasticity } \\
\text { Modulus } \\
\left(\mathrm{Kg} / \mathrm{m}^{2}\right)\end{array}$ & $\begin{array}{l}\text { Poisson } \\
\text { Ratio }\end{array}$ & $\begin{array}{c}\text { Yield stress } \\
\left(\mathrm{Kg} / \mathrm{m}^{2}\right)\end{array}$ & $\begin{array}{l}\text { Tangent } \\
\text { Modulus }\end{array}$ & $\begin{array}{l}\text { Friction } \\
\text { coefficient }\end{array}$ \\
\hline A-Foundation (lose- sand saturated) & 800 & $3 * 10^{6}$ & 0.25 & $1.20 * 10^{4}$ & 0.01 & 0.30 \\
\hline B- Foundation (lose-sand saturated) & 800 & $3 * 10^{6}$ & 0.25 & $1.20 * 10^{4}$ & 0.01 & 0.001 \\
\hline C-Embankment (Clay saturatated) & 900 & $2 * 10^{6}$ & 0.45 & $8.00 * 10^{3}$ & 0.01 & 0.001 \\
\hline D1-Embankment ( un saturatated) & 1900 & $4 * 10^{5}$ & 0.30 & $1.60 * 10^{3}$ & 0.01 & 0.001 \\
\hline D2-Embankment ( un saturatated) & 1900 & $6 * 10^{5}$ & 0.30 & $2.40 * 10^{3}$ & 0.01 & 0.001 \\
\hline D3- Embankment(saturatated) & 1900 & $6 * 10^{5}$ & 0.48 & $2.40 * 10^{3}$ & 0.01 & -..-- \\
\hline E- Water & 1000 & $1 * 10^{12}$ & 0.001 & ---.-- & ------ & -..-- \\
\hline
\end{tabular}

This research introduced non-linear behavior of soil and there are items such as density, Yang modulus and poisson's ratio; yield stress with tangent modulus for bilinear isotropic hardening for solid material was used so huge elasticity modulus for non compact behavior of water according to a suggestion of the help menu of ANSYS was used. Moreover, Figure2 is described to non linear behavior of soil to evaluate analysis and explained behavior of materials in table2. This figure had performance two parts such as a line (L1) for elastic and line (L2) to present of elasto-plastic and plastic conditions. Line (L1) was led to Yang's modulus and $\sigma 1$ with A poisson's ratio, and line(L2) was a simplification of non linear behavior with gradient slope that means of tangent modulus for modeling with bilinear isotropic hardening for solid material in the ANSYS software. It noted 'that' value of $\sigma 2$ was equal to two times of value of $\sigma 1$ and it was obvious 'that' $\sigma 1$ was related to elastic stress according to fixed strain 'that' it was $0.2 \%$ ( laboratory test). Also, $\sigma 2$ was illustrated ultimate stress according to gradient slope of line(L2) so horizontal and vertical direction represented strain and stress respectively.

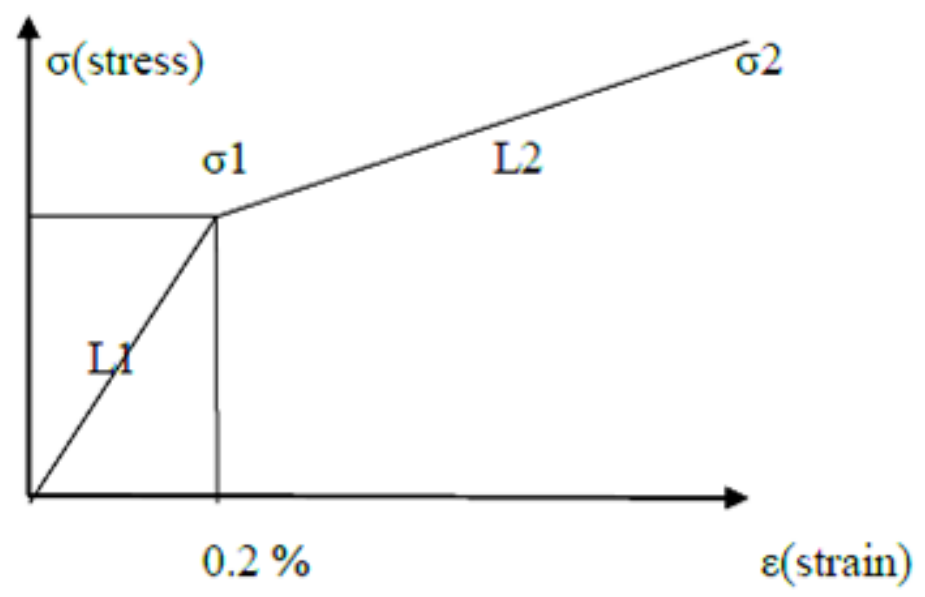

Fig. 2: This figure illustrated non-linear property of soil.

2-6 Meshing and main points

Five main points (1-5) to evaluate exist data were chosen that both were in the crest(1-2) and another was the middle of zones in D, C and A(3-4-5) so Figure3 is illustrated main point's location. Also, Figure4 illustrated that plan mesh is performed with the regular method for effect of interaction and node to node meshing was used. 


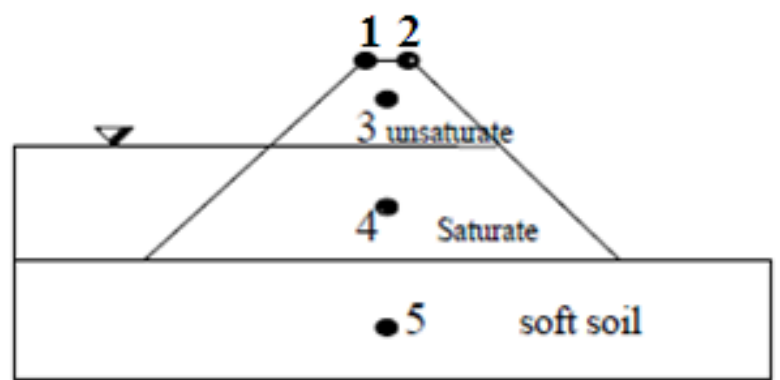

Fig. 3: This figure shown five main points for exist data.

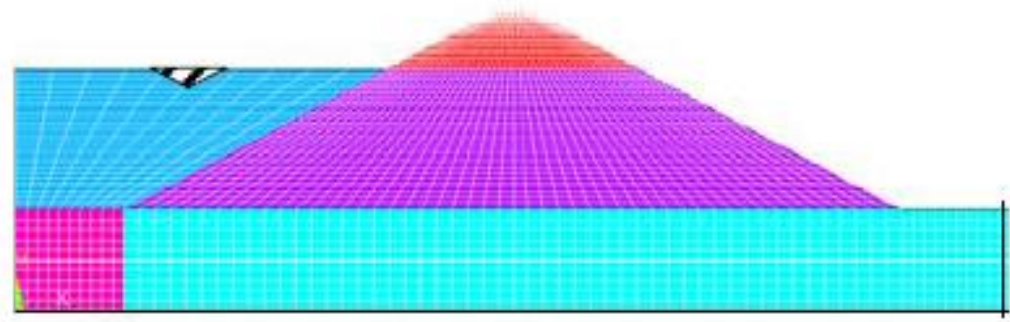

Fig. 4: This figure illustrated that mesh of the model with the regular method.

\section{2-7 Dynamic load}

All models were evaluated by NAGAN record. This record had an acceleration-time with PGA= 0.65 and 5.02 second for time. Moreover, record is converted to displacement-time for input data in ANSYS by SISMOSOFT3 software. Figure5 illustrated that NAGAN record with time acceleration to time displacement was converted. Figure6 indicated that maximum and minimum displacement was $16.5 \mathrm{~mm}$ and $11 \mathrm{~mm}$ respectively. All the sub steps were 0.02 and record was covered 5.02 second, and PGA $=0.65 \mathrm{~g}$ so PGA peaked at ground acceleration.

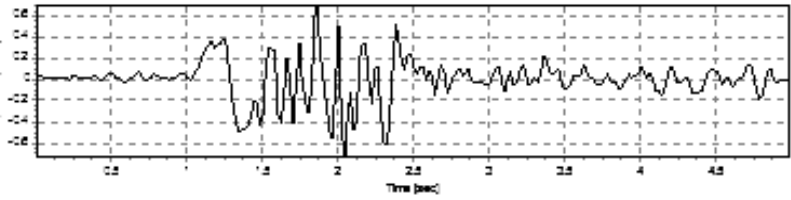

A) Time-acceleration

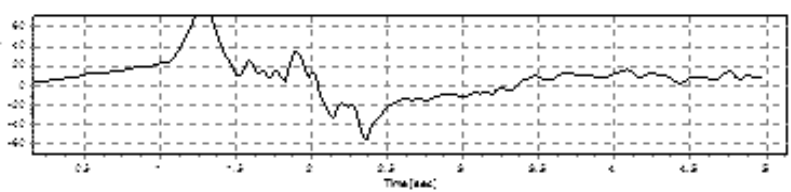

B) Time-velocity

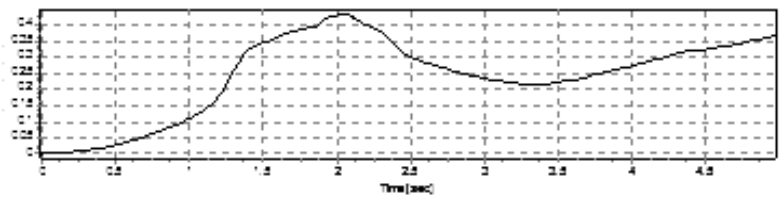

C) Time-Total displacement

Fig. 5: Convert acceleration-time to displacement-time curve by Sismosoft3 and in the (a-c )conditions, horizontal direction is the time(second) and vertical axis are acceleration $(\mathrm{g})$, velocity $(\mathrm{m} / \mathrm{s})$ and total displacement $(\mathrm{cm})$ respectively. 


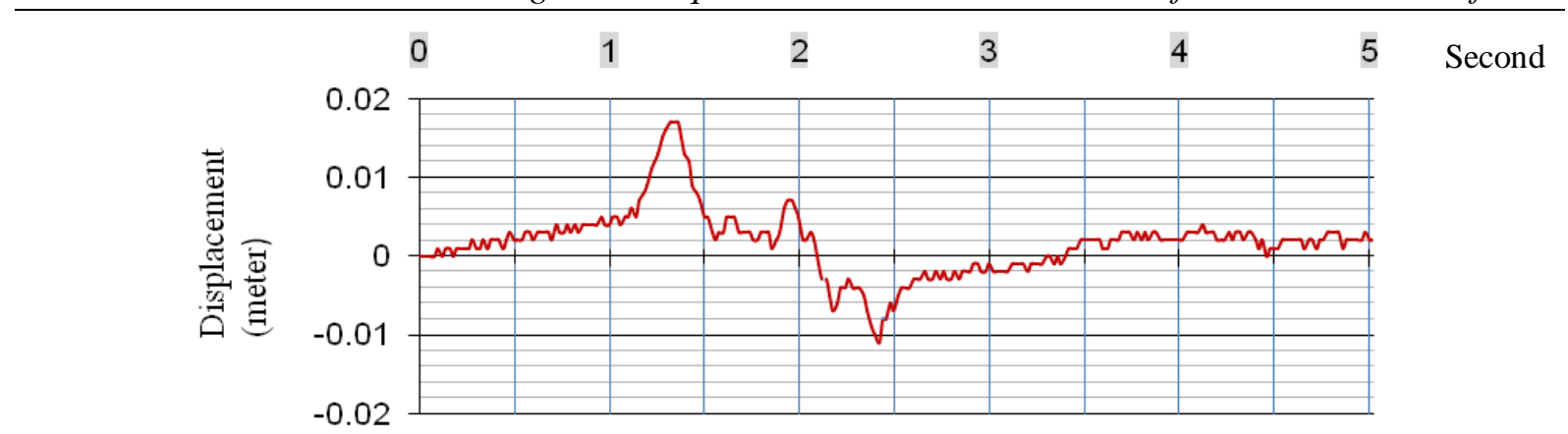

Fig. 6: This is related to inputting data of NAGAN earthquake record according to displacement in the vertical axis(m) and time in the horizontal axis(second).

\section{2-8 Chart of numerical modeling}

This chart introduced a process of numerical modeling, and Figure6 illustrated that it included five steps such as input data, transient analysis, exist data, results and conclusion.

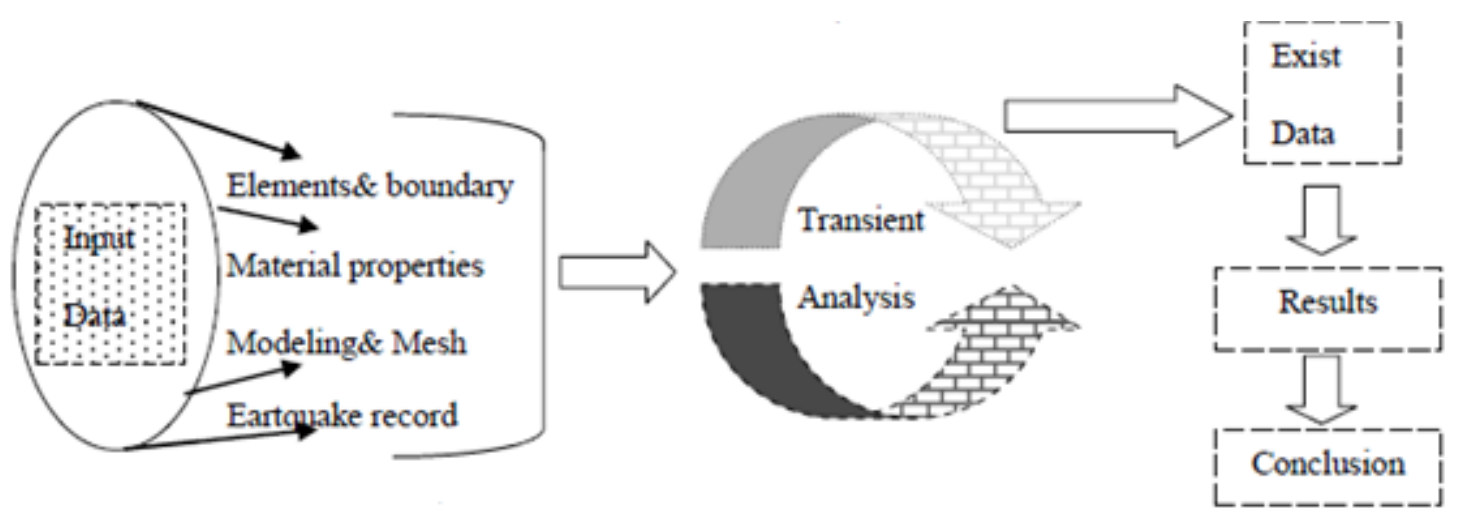

Fig. 7: Process of numerical analysis.

\section{RESULTS ANALYSIS}

Numerical analyses in models were calculated by Nagan record with displacement-time. Moreover, Figures 8 and 9 illustrated non-linear behavior of material during dynamic load for vertical displacement in point 4 and shear stress in point 5 respectively.

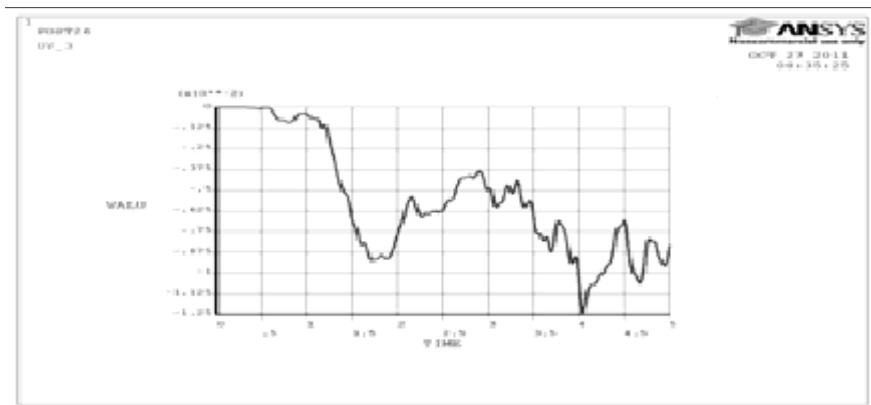

Fig. 8: Vertical displacement-time in the point 4 to analysis settlement during the earthquake so horizontal axis is the time (second) and vertical axis is displacement(meter).

Also, Figure9 illustrated that value of shear stress during dynamic loading. This figure presented value of the XY Shear stress in each sub step of dynamic load and indicated that some of the sub steps were positive or negative value, and it was related to non-linear behavior of analysis during the earthquake. All the nodes had a same and regular process. In addition, this function was very great to analysis by ANSYS. 


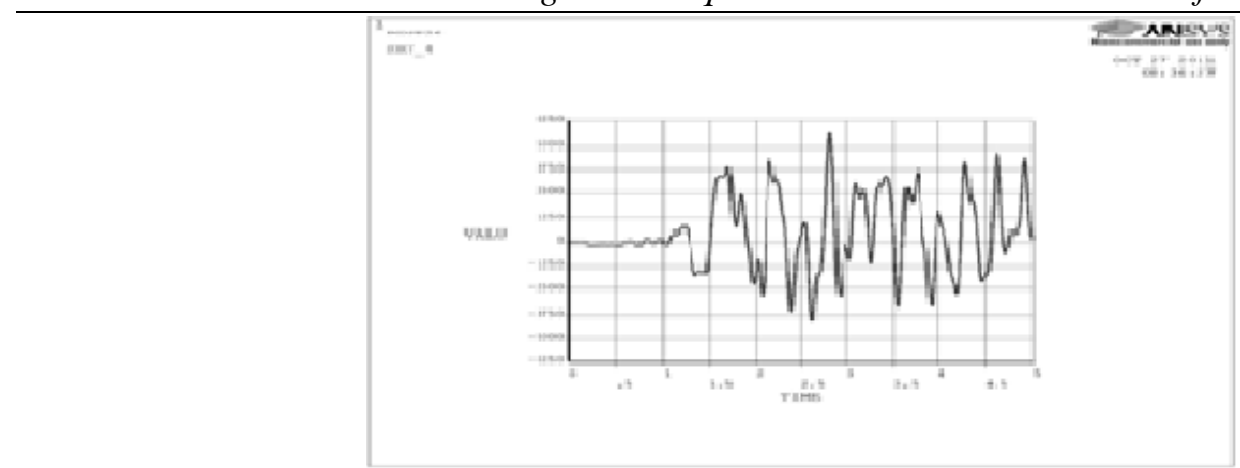

Fig. 9: XY Shear stress in the point 5, in the end sub step of earthquake so horizontal axis is the time (second) and vertical axis is XY Shear stress $\left(\mathrm{Kg} / \mathrm{m}^{2}\right)$.

Due to analysis and evaluation of elasticity modulus $(\delta)$ ratio is presented by:

$$
\text { (Equation-1) } \quad \delta=\frac{(\text { Elastisity modulus })_{E}}{\text { (Elastisity modulus })_{F}}
$$

In fact, $\delta$ is related to the ratio between elasticity modulus in the unsaturated crest of embankment (E) and soft sand soil in the foundation(F). All the results for models(1-3) were leaded to series1-3 respectively.

It was obvious that value of horizontal displacement in model1(minimum modulus elasticity) is less than model 2 and model 3 so it was related to $\delta$ Ratio and increase of this ratio cased to more value of the horizontal displacement. In add, maximum horizontal displacement was related to point4 so it was in the middle of saturated embankment and near to the best effective at water pressure according to static pressure in the $1 / 3$ of height embankment that was clearly in the literature review. Furthermore, increase of the $\delta$ Ratio led to reduce of horizontal displacement in the middle of sand foundation so it was not important because all results in the poin 5 were minimum value. Variant value of the poisson's ratio between model 2 and 3 is conducted to affect of unsaturated and saturate part in the top of embankment, and results indicated that poisson ratio is in depended on the value of horizontal displacement during earthquake and value of modulus elasticity was so efficiency in the control horizontal dynamic displacement. However, the best value of ratio $(\delta=0.13)$ to control horizontal dynamic displacement of embankment was suggested for short embankment saturate. Compare of the horizontal displacement results for all of models is illustrated by Figure 10.

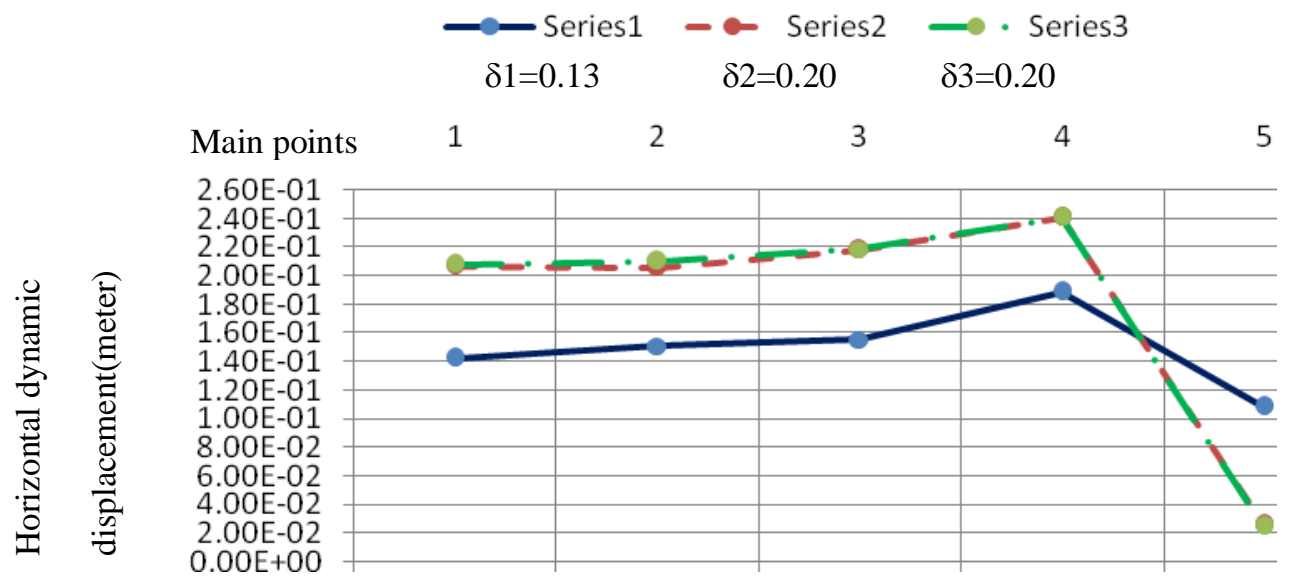

Fig. 10: shown horizontal displacement $(\mathrm{m})$ in the end of dynamic load for models. Horizontal axis is main points, and vertical axis is horizontal dynamic displacement (meter).

Figure11 illustrated vertical displacement or dynamic settlement for models. It is obvious that value of settlement in model 1 is more than model 2 and model 3 in the crest so it was related differential value of modulus elasticity and this ratio. Modulus elasticity and Ratio in the model 1 was less than model2, and it was cased to increase the value of vertical displacement in model 1 rather than model 2 because reduction of modulus cased to increase of flexibility and minimum settlement. Furthermore, maximum settlement is conducted at the crest for all models, and it was indicated that results were validated with literature review. In addition, in all models value of the settlement in the both of points in the crest(1and 2) were not equal, and it was another validate of results according to literature. Figure12 is related to cracks in the crest of an embankment in India so differential settlement in the crest was cased [16]. Moreover, compare of results between model 2 and 3 indicated that value of the poisson's ratio in depended to dynamic settlement, and differential settlement between points (1 and 2) in 
Settlement during an earthquake in the un saturated crest of embankment on soft soil

the crest is same approximately but this value in point 1 from model 2 was more than model 3 and in point 2 it was reverse. Finally, the best value of ratio $(\delta=0.20)$ to control vertical dynamic displacement of embankment was suggested for short height of the saturate embankment.

\begin{tabular}{|c|c|c|}
\hline$\longrightarrow$ Series 1 & - $\bullet$ Series2 & $\longrightarrow$ Series3 \\
\hline$\delta 1=0.13$ & $\delta 2=0.20$ & $\delta 3=0.20$ \\
\hline
\end{tabular}

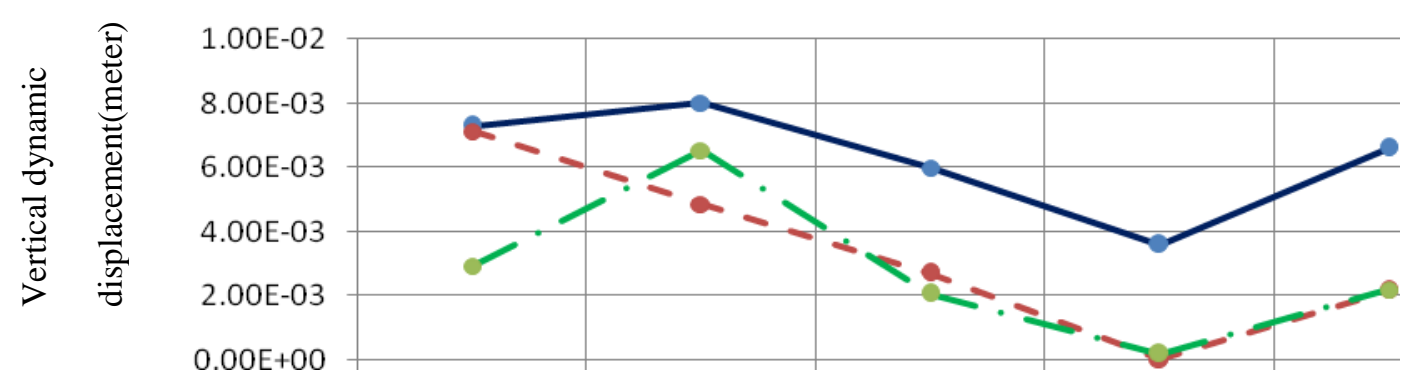

Fig. 11: Vertical dynamic displacement in the end of earthquake for models. Horizontal axis is main points, and vertical axis is dynamic settlement displacement (meter).

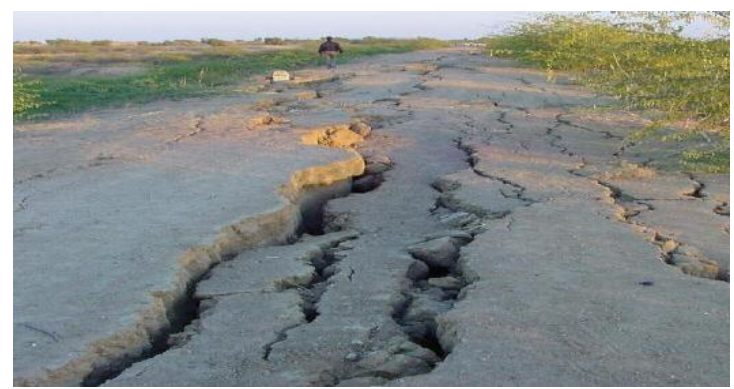

Fig. 12: Cracking and inelastic deformations of crest of the embankment dam caused by the 2001 Bhuj earthquake in India. The prediction of cracks and damage requires nonlinear dynamic analyses and modelling of dam materials. It was sorted by[18].

The value of shear stress in models was illustrated in Figure 13 and maximum values were related in the middle of foundation. Reduce the rate of ratio cased to reduce of shear stress for plan strain analysis of models, and it was obvious that this value in the models (2-3) was four times of model 1 so the best value of the ratio was 0.13 only to control the shear stress was suggested for short height of the saturate embankment.
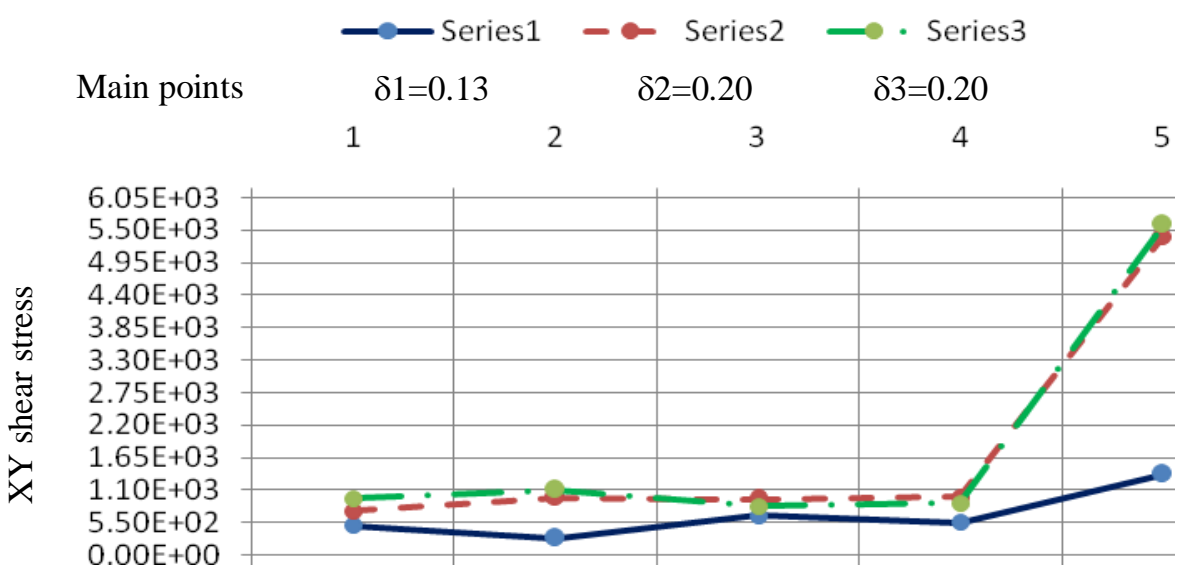

Fig. 13: shown XY Shear stress in the end of the earthquake for models. Horizontal axis is main points, and vertical axis is XY Shear stress $\left(\mathrm{Kg} / \mathrm{m}^{2}\right)$.

Moreover, value of shear strain in models was represented in the Figure 14. Maximum value was related in the middle of foundation. Reduce the rate of $\delta$ Ratio cased to increase of shear strain for plane strain analysis of 
Settlement during an earthquake in the un saturated crest of embankment on soft soil

models. However, Limitation of strain value was so small during the earthquake and the best value of ratio $(\delta=0.20)$ to control shear strain was suggested for short height of the saturate embankment.

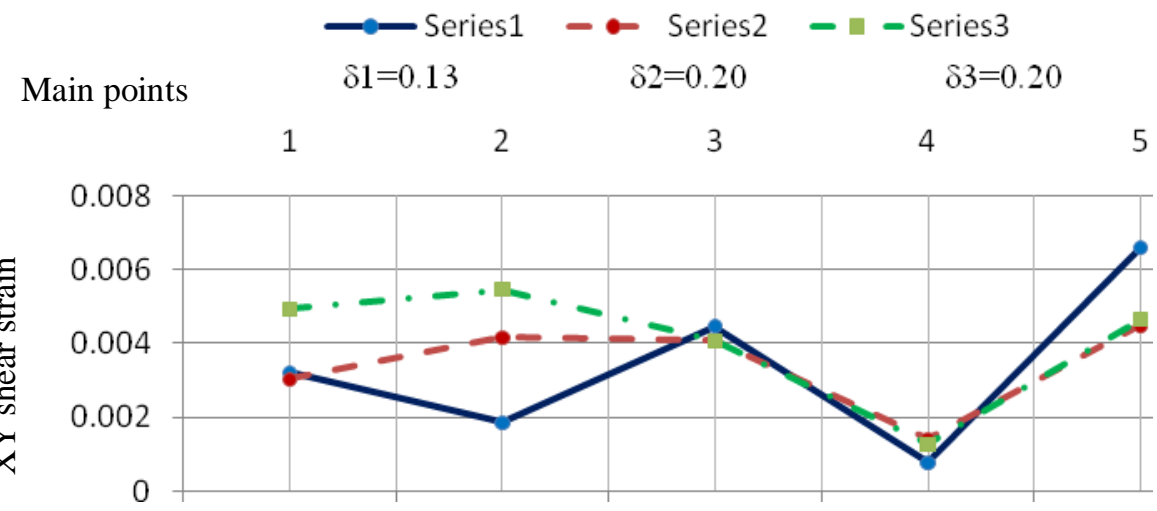

Fig.14: shown XY Shear strain in the end of earthquake for both of models. Horizontal axis is main points, and vertical axis is XY Shear strain.

\section{CONCLUSIONS}

Dynamic analysis of short embankment with saturate material properties in the body, and soft soil foundation is considered. Results conducted that displacements, and shear stresses were depended on the $\delta$ Ratio, and it was related to modulus elasticity between up to part of embankment and foundation. Comparison of results in the main points of plan strain dynamic analysis indicated that to control dynamic settlement with minimum value of displacement in the vertical and horizontal axis and maximum shear stress in the foundation must follow of the Ratio and this value between 0.13 to 0.20 was obtained. The best suggest of the ratio was $\delta=0.16$ (average) to satisfy all the conditions. In addition, numerical analysis had a good agreement with literature review. Search to evaluate the best value of this Ratio for height embankment is a suggestion for future.

\section{REFERENCE}

[1]. Newmark, N.M., (1965). Effects of earthquakes on dams and embankments. Geotechnique, 15: 139-160. http://www.civil.ubc.ca/liquefaction/Publications/H yropower\&Dams.pdf

[2]. Mononobe, H.A., (1936). Seismic stability of the earth dam. Proceeding of the 2nd Congress on Large Dams, (CLD’36), Washington DC., USA., pp: 435-442.

[3]. Gazetas, G., (1981). A new dynamic model for earth dams evaluated through case histories. Soils Foundat.,21: 67-78. http://ci.nii.ac.jp/naid/110003914595

[4]. Clough, R.W. and A.K. Chopra, (1966). Earthquake stress analysis in earth dams. J. Eng. Mech., ASCE., 92: 197-211. http://nisee.berkeley.edu/elibrary/Text/300451

[5]. Zeghal, M. and A.M Abdel-Ghafar, (1992). Local global finite element analysis of the response of earth dams. Comput. Struct.,42:569-579.DOI: 10.1016/0045-7949(92)90124-I

[6]. Ming, H.Y. and X.S. Li, (2003). Fully coupled analysis of failure and remediation of lower San Fernando dam. J. Geotechnic. Eng. Div., ASCE., 129: 336-349. DOI: 10.1061/(ASCE) 1090-0241(2003)129: 4(336)

[7] J.L. Borges(2004).Three-dimensional analysis of embankments on soft soils incorporating vertical drains by finite element method. Computers and Geotechnics 31 (2004)665-676 www.elsevier.com/locate/compgeo

[8] A. Yildiz (2009). Numerical analyses of embankments on PVD improved soft clays. Advances in Engineering Software 40 (2009)1047-1055 Journal homepage: www.elsevier.com/locate/advengsoft

[9]. Ordóñez, G.A., (2000). SHAKE2000: A computer program for the 1D analysis of geotechnical earthquake engineering problems. http://www.shake2000.com/index.htm

[10] R. Noorzad and M. Omidwar (2010). Seismic displacement analysis of embankment dams with reinforced cohesive shell. Soil Dynamics and Earthquake Engineering 30 (2010) 1149-1157 journal homepage: www.elsevier.com/locate/soildyn

[11] Z.F. Xia, G.L. Ye, J.H .Wang, B. Ye and F. Zhang (2010). Fully coupled numerical analysis of repeated shake-consolidation process of earth embankment on liquefiable foundation. Soil Dynamics and Earthquake Engineering 30 (2010) 1309-1318 journal homepage: www.elsevier.com/locate/soildyn

[12] A. Namdar and A. k. Pelko (2010). Seismic Evaluation of Embankment Shaking Table Test and Finite Element Method. The Pacific Journal of Science and Technology - volume11, Number2, November 2010 http://www.akamaiuniversity.us/PJST.http

[13] L. Wang, G. Zhang and J.M. Zhang(2010). Centrifuge model tests of Geotextile-reinforced soil embankments during an earthquake. Journal Geotextiles and geomembranes 29 (2010) 222-232 www.elsevier.com/locate/geotexmem

[14]. Zhu, Y., K. Lee and G.H. Collison, (2005). A 2D seismic stability and deformation analysis. Proceeding of the Geo-Frontiers, Jan. 24-26, ASCE., Austin, Texas, pp: 1-15.

http://www.golder.com/archive/2005Geo_PTFI.pdf

[15]. Brinkgreve, R.B.J., R. Al-Khoury, K.J. Bakker, P.G. Bonnier and P.J.W. Brand et al., (2002). PLAXIS 2D-version 8 full manual. Netherlands.

[16] Mestat, ph.(1993), "Lois des Comportement des Geomateriaux et Modelisation Par La Methode des Elements finis", Etudes et Recherches des Laboratories des Ponts et Chaussees- Serie Geotechnique:GT52

[17]. M. Wieland,(2008).Analysis aspects of dams subjected to strong ground shaking. waterpowermagazine.com 